\title{
Microvascular Angina in a Patient With Aortic Stenosis
}

\author{
Riichirou Kawamoto, MD; Takuroh Imamura, MD; Kuniasa Kawabata, MD; \\ Haruhiko Date, MD; Tetsunori Ishikawa, MD; Masakazu Maeno, MD; \\ Toshiro Nagoshi, MD; Yoshitake Fujiura, MD; Akihiko Matsuyama, MD; \\ Takeshi Matsuo, MD; Yasushi Koiwaya, MD; Tanenao Eto, MD
}

\begin{abstract}
A 39-year-old woman had exercise-induced ST segment depression associated with chest pain. Cardiac evaluation revealed moderate aortic stenosis (AS), related to the bicuspid valves, with an aortic mean pressure gradient of 22 $\mathrm{mmHg}$, a calculated aortic valve area of $1.3 \mathrm{~cm}^{2}$ and normal left ventricular (LV) peak systolic and end-diastolic pressures, but no LV hypertrophy, resulting in normal LV wall stress. Although the coronary arteries were angiographically normal, rapid atrial pacing and an intracoronary papaverine injection revealed a significantly decreased coronary flow reserve (CFR), which may have played an important role in the pathogenesis of angina pectoris in this patient. Though the CFR is usually decreased in patients with AS, as well as in microvascular angina, in this particular case, it appeared to have decreased as a consequence of microvascular dysfunction rather than of AS-related mechanisms. (Jpn Circ J 2001; 65: 839-841)
\end{abstract}

Key Words: Aortic stenosis; Coronary flow reserve; Doppler flow wire; Microvascular angina; Papaverine

$\mathbf{T}$ he reported incidence of angina pectoris (AP) in patients with aortic stenosis (AS) and normal coronary arteries varies from $30 \%$ to $40 \%,{ }^{1-3}$ but the pathogenesis of this association remains unclear. AP may be caused by mismatched demand and supply of myocardial oxygen, particularly in response to stress $4,5 \mathrm{An}$ increase in left ventricular (LV) peak systolic pressure (LVPSP), LV mass, and LV ejection time (LVET) increases myocardial oxygen demand; decreased diastolic time resulting from the increased LVET and increased LV end-diastolic pressure (LVEDP) decreases myocardial oxygen supply 5 Coronary flow reserve (CFR) is also impaired in severe AS $^{6-9}$ These mechanisms have been explained by LV hypertrophy $(\mathrm{LVH})$ or an increased LV mass ${ }^{6,7}$ and by hemodynamic factors, such as elevated LVPSP and LVEDP, and wall stress. ${ }^{8} 9$ Marcus et al speculated that the coronary flow to the hypertrophied myocardium is already significantly increased at rest and cannot further increase in response to coronary vasodilation? On the other hand, Julius et al proposed that myocardial ischemia in patients with severe AS, but not LVH, could occur because of the high LVPSP and LVEDP, resulting in high systolic and diastolic wall stress and a consequent reduction in CFR? These findings imply that the cause of AP in patients with AS who have normal coronary arteries is attributable to LVH and/or high wall stress ${ }^{10}$

The condition that features angina or angina-like chest pain and ischemic ST segment depression on electrocardiography (ECG) during exercise, together with angiographically normal coronary arteries without coronary spasm, is sometimes called syndrome $\mathrm{X}{ }^{11,12}$ Cannon et al referred to a clinical entity satisfying the criteria of syndrome $X$, and

(Received January 29, 2001; revised manuscript received March 2, 2001; accepted March 8, 2001)

First Department of Internal Medicine, Miyazaki Medical College, Miyazaki, Japan

Mailing address: Tanenao Eto, MD, First Department of Internal Medicine, Miyazaki Medical College, 5200 Kihara, Kiyotake, Miyazaki 889-1692, Japan with myocardial ischemia caused by a disorder of the coronary microvasculature, as microvascular angina (MVA)! ${ }^{13}$ Microvascular dysfunction is characterized by an inadequate vasodilator response, such as impaired CFR ${ }^{13-16}$ or the production of myocardial lactate, $, 2,13,17$ in response to dynamic exercise ${ }^{18}$ or metabolic and pharmacological stimuli $^{13}$ We describe a patient with moderate AS associated with AP who showed neither LVH nor high wall stress.

\section{Case Report}

Severe AS was suspected in a 39-year-old woman who visited her local clinic with heart murmur, exercise-induced dyspnea and chest pain. She was referred to hospital for
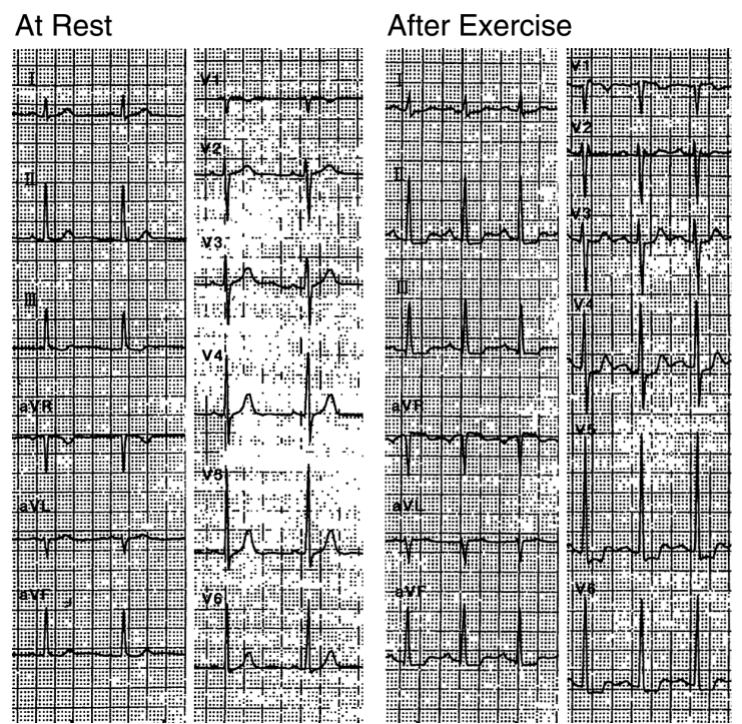

Fig 1. Twelve-lead ECG at rest and immediately after exercise. STsegment depression with chest pain after exercise can be seen in leads II, III, $\mathrm{aVF}$ and $\mathrm{V}_{4-6}$. 

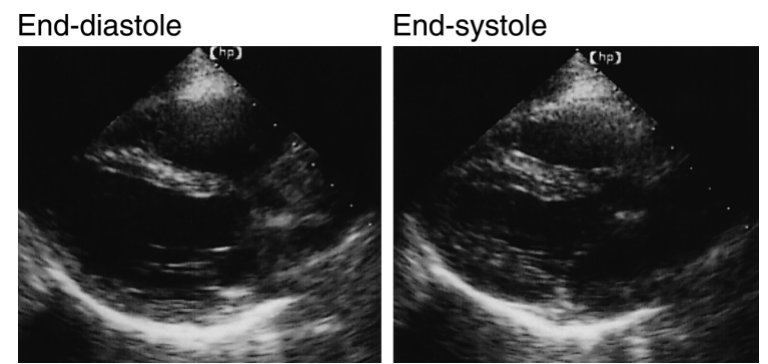

Fig 2. Echocardiography in the end-diastolic and end-systolic phases shows normal systolic (EF: 76\%) and diastolic (deceleration time $=$ $190 \mathrm{~ms}$ ) function and wall thickness of LV (thickness of interventricular septum, $11 \mathrm{~mm}$; thickness of LV posterior wall, $10 \mathrm{~mm}$ ). The left ventricular cavity is not enlarged (LV diastolic dimension, $43 \mathrm{~mm}$; LV systolic dimension, $24 \mathrm{~mm}$ ). The mean pressure gradient (PG) between the aortic valves was $20 \mathrm{mmHg}$ ( $\mathrm{max}$ PG: $42 \mathrm{mmHg}$ ) and aortic valve area was $1.2 \mathrm{~cm}^{2}$ (calculated using continuity equation).
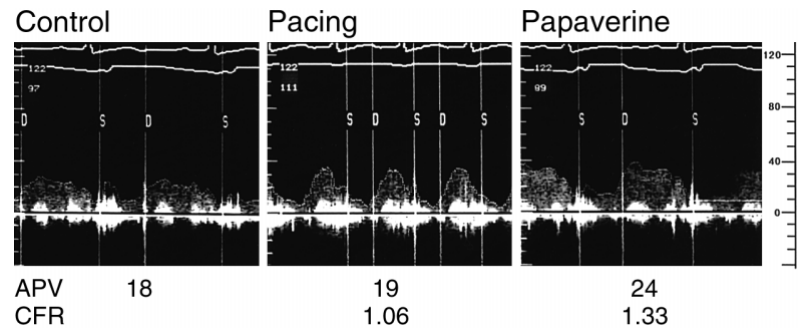

Fig 3. Coronary flow velocity recordings at rest, after pacing, and after intracoronary papaverine injection. Compared with control values, the time-averaged peak velocity (APV) and coronary flow reserve (CFR) after pacing and papaverine did not significantly increase.

further cardiac evaluation. Physical examination revealed a heart rate $(\mathrm{HR})$ of 60 beats/min and blood pressure of $126 / 88 \mathrm{mmHg}$. A grade 3/6 ejection-type systolic murmur was audible at the $3 \mathrm{rd}$ left intercostal space with radiation to the neck. Chest X-ray demonstrated slight cardiomegaly with a cardiothoracic ratio of $52 \%$, but no pulmonary congestion. ECG showed normal sinus rhythm at rate of 72 beats/min, normal axis, and depressed ST segment in leads II, III aVF, and V4-6 with chest pain and dyspnea after exercise (Fig 1). Echocardiography documented moderate AS with mean pressure gradient (PG) across the aortic valve of $20 \mathrm{mmHg}$ (max PG: $42 \mathrm{mmHg}$ ), and the aortic valve area (AVA) calculated using the continuity equation was 1.2 $\mathrm{cm}^{2}$. The systolic and diastolic functions, as well as the wall thickness, of the LV were all within normal limits (ejection fraction (EF), 76\%; deceleration time, $190 \mathrm{~ms}$; thickness of the interventricular septum, $11 \mathrm{~mm}$ and thickness of LV posterior wall, $10 \mathrm{~mm}$ ) (Fig 2). The LV cavity was not enlarged (LV diastolic dimension, $43 \mathrm{~mm}$; LV systolic dimension, $24 \mathrm{~mm}$ ). A cardiac catheterization study showed LVPSP, LVEDP, mean PG across the aortic valve and a calculated AVA of $125 \mathrm{mmHg}, 4 \mathrm{mmHg}, 22.1 \mathrm{mmHg}$ and $1.29 \mathrm{~cm}^{2}$, respectively. The values for meridional endsystolic and end-diastolic wall stress were calculated as 56.7 and $9.5 \mathrm{kdynes} / \mathrm{cm}^{2}$, respectively, using Grossman's equation 19 Coronary arteriography revealed neither organic stenosis nor coronary spasm in response to injected ergonovine malate. Left ventriculography revealed normal wall motion, an EF of $78 \%$, and bicuspid aortic valves.

We evaluated the coronary microcirculation by atrial pacing and also by intracoronary injection of papaverine. Rapid atrial pacing was performed until the HR reached 150 beats/min and papaverine $(10 \mathrm{mg}$ ) was injected into the left anterior descending artery over a period of $90 \mathrm{~s}$. Coronary blood flow was measured using a 15-MHz Doppler wire (FlowWire. 0.014 inch, Endosonics, Inc, USA) and CFR was obtained from the hyperemia/baseline flow ratio. Coronary flow velocity did not increase after rapid atrial pacing at 150 beats/min, when chest pain with ST-segment depression developed. The calculated CFR was 1.06 during rapid atrial pacing and 1.33 after papaverine injection (Fig 3). In addition, coronary arterial and coronary sinus blood were simultaneously collected to evaluate lactate production, but it was not produced after pacing and the papaverine injection, despite the decrease in CFR. These findings indicated a diagnosis of MVA associated with moderate AS.

\section{Discussion}

Patients with severe AS may be asymptomatic for many years despite severe obstruction, but once symptoms, such as angina, heart failure and syncope, manifest in such patients, the prognosis is poor. Aortic valve replacement is generally recommended, so the development of angina is a critical point in the natural history of AS5 Severe AS was initially suspected in the present patient, because of the grade 3/6 systolic murmur and effort angina, but in fact was not severe. Neither LVH nor increased wall stresses was evident, although the CFR was significantly decreased. Because CFR is decreased in patients with MVA, ${ }^{13-16}$ as well as in those with $\mathrm{AS}^{6-9}$ the cause in the present patient could have been either. Resting coronary flow to the hypertrophied myocardium in patients with AS is already significantly increased and cannot increase during tachycardia? Hittingen et al recently demonstrated in dogs with chronic pressure-overloaded LVH that hemodynamic factors, such as compressive forces, rather than structural factors such as hypertrophy, are critical in mediating reduced subendocardial CFR? Furthermore, myocardial ischemia in severe AS without LVH has been proposed by Julius et al? who suggested that increased wall stress resulting from augmented LVPSP and LVEDP without the corresponding LVH plays a primary role in mediating abnormal CFR? This is because the LV wall stress is most simply described by the following LaPlace relationship: $(\mathrm{P} \times \mathrm{R}) / 2 \mathrm{H}$, where $\mathrm{P}$ is pressure, $R$ is the radius of the $\mathrm{LV}$ and $\mathrm{H}$ is the thickness of the $\mathrm{LV}$ wall20 Thus, the possible cause of decreased CFR in patients with AS could be either LVH or high wall stresses. Because the LVPSP, LVEDP, LV wall thickness, and LV dimension of the present patient described were all within normal ranges, the end-systolic and end-diastolic wall stresses were normal. These hemodynamic and structural data suggest that the cause of the impaired CFR in this patient was not AS-related.

MVA is caused by a disorder of the coronary microvasculature that is characterized by impaired CFR or lactate production in response to dynamic exercise ${ }^{18}$ or metabolic and pharmacological stimuli13 ${ }^{3}$ However, the cause of the impaired CFR in MVA remains unclear and so a diagnosis of MVA can vary considerably among institutions depending upon the method(s) used. Nonetheless, Masseri et al proposed that in patients with MVA arteriolar vessels involved in the metabolic autoregulation of flow are already dilated to preserve myocardial flow in the resting state, 
because patchily distributed and abnormally constricted coronary prearteriolar vessels decrease the distal pressure of arteriolar vessels ${ }^{21}$ This is because of the general relationship: flow $=$ pressure gradient $/$ resistance. Ischemia or coronary steal can develop in patients with MVA when metabolic or pharmacological arteriolar vasodilation causes an excessive reduction in the pressure of arterioles distal to the constricted prearteriolar vessels? ${ }^{2}$ This mechanism may account for the MVA in the present patient, but, although decreased CFR associated with chest pain and ischemic changes on ECG were induced by rapid atrial pacing, myocardial lactate was not produced. An intracoronary injection of papaverine revealed the reduced CFR without lactate production. Cannon et al reported that the prevalence of abnormal responses in coronary flow and lactate production during rapid pacing in the same patient with MVA differs, suggesting that hemodynamic and metabolic abnormalities are not consistent features of MVA $!^{3} \mathrm{~Pa}$ paverine may interfere with oxygen transport or uptake and may induce cellular hypoxia.2 However, as the incidence of myocardial ischemia confirmed by lactate production in patients with MVA ranges from 22 to $100 \%, 12,13,17$ the difference depends on the choice of diagnostic method and patient group. On the bases of these considerations, we speculate that the pathogenesis of AP in this patient was a product of microvascular dysfunction rather than ASrelated mechanisms.

AP in patients with AS usually appears at an advanced stage of the disease. The present patient had moderate AS and AP. The coronary arteries were angiographically normal and CFR was reduced. AP can develop as a consequence of microvascular dysfunction rather than as a result of ASrelated mechanisms. The mechanism of AP in individual patients with AS is heterogeneous. Alternatively, it may develop in patients with non-severe AS.

\section{Acknowledgments}

We thank Dr Yuji Matsuoka for referring a patient to us and Ms Norma Foster for assistance with the manuscript.

\section{References}

1. Hakki A-H, Kimbiris D, Iskandrian AS, Segal BL, Mintz GS, Bemis $\mathrm{CE}$ : Angina pectroris and coronary artery disease in patients with severe aortic valvular disease. Am Heart J 1980; 100: 441-449

2. Mandel AB, Gray IR: Significance of angina pectoris in aortic valve stenosis. Br Heart J 1976; 38: 811 -815

3. Nadell R, DePace NL, Ren JF, Hakki A-H, Iskandrian AS, Morganroth $\mathrm{J}$ : Myocardial oxygen supply/demand in aortic stenosis: Hemodynamic and echocardiographic evaluation of patients with and without angina pectoris. J Am Coll Cardiol 1983; 2: 258-262
4. Beckberg G, Eber L, Herman M, Gorlin R: Ischemia in aortic stenosis: Hemodynamic prediction. Am J Cardiol 1975; 35: 778-784

5. Braunwald E: Valvular heart disease. In: Braunwald E, editor. Heart disease: A textbook of cardiovascular medicine. Philadelphia: WB Saunders, 1997: 1035-1045

6. Fallen EL, Eiliott WC, Gorlin R: Mechanisms of angina in aortic stenosis. Circulation 1967; 36: 480-488

7. Marcus ML, Doty DB, Hiratzka LF, Wright GB, Eastham GL: Decreased coronary reserve: A mechanism for angina pectoris in patients with aortic stenosis and normal coronary arteries. $N$ Engl J Med 1982; 307: 1362-1367

8. Hittinger L, Mirsky I, Shen YT, Patrick TA, Bishop SP, Vatner SF: Hemodynamic mechanisms responsible for reduced subendocardial coronary reserve in dogs with severe left ventricular hypertrophy. Circulation 1995; 92: 978-986

9. Julius BK, Spillmann M, Vassalli G, Villari B, Eberli FR, Hess OM: Angina pectoris in patients with aortic stenosis and normal coronary arteries: Mechanisms and pathophysiological concepts. Circulation 1997; 95: 892-898

10. Gould KL: Why angina pectoris in aortic stenosis. Circulation 1997; 95: $790-792$

11. Likoff W, Segal BL, Kasparian H: Paradox of normal selective coronary arteriograms in patients considered to have unmistakable coronary heart disease. N Engl J Med 1967; 276: $1063-1066$

12. Kemp HG Jr: Left ventricular function in patients with the anginal syndrome and normal coronary angiograms. Am J Cardiol 1973; 32: $375-376$

13. Cannon RO, Epstein SE: 'Microvascular angina' as a cause of chest pain with angiographically normal coronary arteries. Am J Cardiol 1988; 61: 1338-1343

14. Chauhan A, Mullins PA, Petch MC, Schofield PM: Is coronary flow reserve in response to papaverine really normal in syndrome $\mathrm{X}$ ? Circulation 1994; 89: 1998-2004

15. Camici PG, Gistri R, Lorenzoni R, Sorace O, Michelassi C, Bongiorni MG, et al: Coronary reserve and exercise ECG in patients with chest pain and normal coronary angiograms. Circulation 1992; 86: 179186

16. Baumgart D, Haude M, Liu F, Ge J, George G, Erbel R: Current concepts of coronary flow reserve for clinical decision making during cardiac catheterization. Am Heart J 1998; 136: 136-149

17. Greenberg MA, Grose RM, Neuberger N, Silverman R, Strain JE, Cohen MV: Impaired coronary vasodilator responsiveness as a cause of lactate production during pacing-induced ischemia in patients with angina pectoris and normal coronary arteries. J Am Coll Cardiol 1987; 9: 743-751

18. Nagayama M, Fujita Y, Kanai T, Yamada T, Tozawa K, Ushiyama $\mathrm{M}$, et al: Changes in myocardial lactate metabolism during ramp exercise in patients with effort angina and microvascular angina. Jpn Circ J 1996; 60: 876-888

19. Grossman W, Jones D, McLaurin LP: Wall stress and patterns of hypertrophy in the human left ventricle. J Clin Invest 1975; 56: 5664

20. Imamura T, McDermott PJ, Kent RL, Nagatsu M, Cooper GIV, Carabello BA: Acute changes in myosin heavy chain synthesis rate in pressure versus volume overload. Circ Res 1994; 75: 418-425

21. Maseri A, Crea F, Kaski JC, Crake T: Mechanisma of angina pectoris in syndrome X. J Am Coll Cardiol 1991; 17: 499-506

22. Christensen VW, Rosen LB, Gal RA, Haseeb M, Lassar TA, Port SC: Coronary vasodilator reserve: Comparison of the effects of papaverine and adenosine on coronary flow, ventricular function, and myocardial metabolism. Circulation 1991; 83: 294-303 